\section{NRC recommends optics and photonics research priorities}

\author{
www.nationalacademies.org
}

$\mathbf{A}^{\mathrm{r}}$ report from the US National Research Council, Optics and Photonics: Essential Technologies for Our Nation, identifies research priorities and grand challenges in the areas of optics and photonics that have the potential to advance the economy of the United States and provide visionary directions for future technology applications. The report recommends that the federal government develop a "National Photonics Initiative" to bring together academia, industry, and government to steer federal research and development funding and activities.

"Much is unknown when pursuing basic optical science and its transition to engineering and ultimately to products, but the rewards can be great," said Alan Willner, professor of electrical engineering at the University of Southern Cali- fornia and co-chair of the committee that wrote the report. "There are a number of opportunities that could change our daily lives."

"People do not think of Google as an optics company, but a typical Google data center has more than a million lasers in it," said Paul McManamon, technology director of the Ladar and Optical Communication Institute at the University of Dayton and committee co-chair. "The Internet example is only one case where work in optics and photonics may be a small part of the money invested in research, but is a critical enabler for high-tech businesses and jobs."

The committee named five grand challenges facing the country that can be addressed with advances in optics and photonics technology. The first is to keep

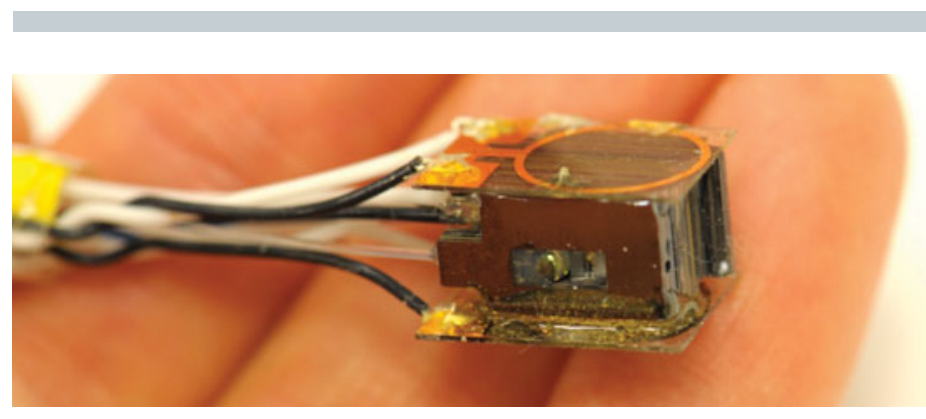

This atom-based magnetic sensor measures human brain activity. Inside the sensor head is a container of 100 billion rubidium atoms (not seen), packaged with micro-optics (a prism and a lens are visible in the center cutout). The light from a low-power infrared laser interacts with the atoms and is transmitted through the gray fiber-optic cable to register the magnetic field strength. Credit: Knappe/NIST

Global uranium supply ensured for long term

www.oecdbookshop.org

$\mathbf{U}$ ranium resources and production are on the rise with the security of uranium supply ensured for the long term, according to a new report by the Organisation of Economic Co-operation and Development Nuclear Energy Agen- cy $(\mathrm{OECD} / \mathrm{NEA})$ and the International Atomic Energy Agency (IAEA).

Uranium 2011: Resources, Production and Demand, commonly referred to as the "Red book," shows that total identified world uranium resources have up the pace of technological achievement established in previous decades. Others include improved military surveillance and missile defense, achieving cost parity for solar power versus fossil fuel-based power across the country's electrical grid, achieving seamless integration of photonics and electronics at the chip level, and developing optical sources and imaging tools to support increased resolution in manufacturing.

Eight particular areas of technological application are discussed in separate chapters: communications, information processing, and data storage; defense and national security; energy; health and medicine; advanced manufacturing; advanced photonic measurements and applications; strategic materials for optics; and displays. Each chapter reviews progress that has occurred since the 1998 National Research Council report, Harnessing Light: Optical Science and Engineering for the 21 st Century, as well as the technological opportunities that have risen from recent advances in optical science and engineering. The report recommends actions for the development and maintenance of global leadership in photonics-driven industries, including both near-term and long-range goals, likely participants, and responsible agents of change.

A National Photonics Initiative will help manage the breadth of rapidly expanding applications of photonics technologies, the report says, allowing both government and industry to form coherent strategies for technology development and deployment. The recommended initiative should also spearhead a collaborative effort to improve the collection and reporting of research, development, and economic data in this sector. 